\title{
Siete estudios sobre transmisión y herencia científica entre Europa y América Latina (1850-1940)
}

\author{
Sonia Lozano \\ Pesquisadora del Centre de Recherche Médecine, Sciences, Santé et Société (Cermes) \\ sonialozanomx@yahoo.com.mx \\ Natalia Priego \\ Pesquisadora del Institute of Latin American Studies, University of Liverpool \\ principe@liverpool.ac.uk
}

B ien que la historia de la ciencia no es una nueva disciplina en los estudios latinoamericanos, esta se ha ido especializando y creando sus propias herramientas de investigación en los últimos treinta años. Así mismo, los historiadores de la ciencia latinoamericanos y latinoamericanistas se han multiplicado y han ido describiendo poco a poco la especificad de las interacciones, de la transmisión y del desarrollo del conocimiento entre los países americanos. Como muestra de ello en 2005 fue incorporada por primera vez la historia de la ciencia en América latina como simposio independiente en el Congreso de Asociación de Historiadores Latinoamericanistas Europeos (AHILAE). Igualmente en 2006 la historia de la ciencia conquistó su espacio en el ultimo Congreso Internacional de Americanistas (ICA). Los artículos contenidos en este numero son una compilación de los trabajos presentados en los congresos antes mencionados, los cuales, dan cuenta de los diferentes campos de interés y puntos de vista que son abordados hoy en la historia de la ciencia latinoamericana. Entre los autores encontramos historiadores, psicólogos, sociólogos y especialistas en ciencias químicas y biológicas, quienes han hecho de la historia de la ciencia su especialidad en sus áreas de conocimiento.

Los artículos que presentamos exploran estilos y vías diferentes de transmisión e intercambios del conocimiento científico, entre Europa y América latina en el siglo XIX (Ismael Ledesma, Sonia Lozano, Natalia Priego y J. Manuel González) o entre los países americanos en el siglo XX (Yajaira Freites, J. José Martin-Frechilla y Elena Quiñones, Maria Peñaranda, Elena García). El punto común de estos textos es que nos muestran, una vez mas, que la recepción, la 'aclimatación' y de difusión de la ciencia en América latina es un proceso dinámico en donde los factores políticos, cientificos y sociales interactúan como las corrientes de un río esculpiendo su lecho. Por otro lado los intercambios y contactos entre los países de América latina es multi-direccional. Estos intercambios son sobretodo una rica fuente de datos ideológicos, sociales, económicos y políticos para la historia latinoamericana en todas sus ramas.

Dentro de los estudios que tratan sobre la introducción de la biología en el siglo XIX en México, Ismael Ledesma-Mateos nos muestra la problemática de la introducción y de la 
asimilación de la biología y de sus paradigmas fundacionales (tales que la teoría celular, la teoría de la homeostasis, la teoría de la evolución y la teoría de la herencia). Para Ledesma la introducción de un conocimiento es un proceso que implica la conjunción de múltiples factores en relación con las características de la comunidad que recibe los nuevos conceptos y las nuevas teorías. Para el autor, durante este proceso, ocurren fenómenos de 'domesticación social' del nuevo conocimiento, que implica operaciones de traducción y de convicción, donde surgirán versiones hibridas, con particularidades locales, distintas a las versiones originales de los países europeos. De tal manera, que en la operación de traducción, la teoría original se modifica con elementos propios del sitio de llegada, como ocurrió con el pensamiento darviniano en México, al que Alfonso Herrera adoso como elemento indisoluble el problema del origen de la vida y su teoría de la plasmogenia.

Sobre las mismas líneas temáticas: la transmisión de conocimientos y los procesos de adaptación, mi artículo presenta uno de los aspectos de la temprana importación de la bacteriología en México en 1880. El contexto es la guerra contre el virus amaril que las naciones americanas emprenden a partir de la publicación del Annual report of the National Board of Health de 1879. El objetivo de este trabajo es describir los problemas epistemológicos y materiales que afrontaron los primeros médicos mexicanos que se sirvieron de la bacteriología para la búsqueda de un método profiláctico contra la fiebre amarilla. Presento algunas de las contradicciones de la primera teoría microbiana de los años 1870 que complicaron la importación y la comprensión de las técnicas bacteriológicas. Por ejemplo, el problema de la inmutabilidad de las especies bacterianas pronunciado por Robert Koch y que no era necesariamente compartido por los pasteurianos o bien la confusión entre el concepto de vacunación de Jenner y las vacunas de los pastoréanos.

Para terminar, sobre la transmisión de conocimientos en el México del Porfiriato (18761911), Natalia Priego define con una gran claridad la construcción ideológica y 'seudocientífica' de la 'identidad mexicana' en ese periodo. Esto con la finalidad de explicar al lector el uso y significado de las diferentes acepciones que la palabra ciencia tuvo como objeto político, social y como garante de la modernización de la nación. Priego nos invita a explorar las contradicciones entre una política científica favorable al desarrollo científico y tecnológico, y la convicción nacional de que la ciencia occidental es el producto terminado de sociedades mas desarrolladas a cuya cultura, sabiduría y modernidad el común de los mexicanos no podía acceder.

Para concluir con los cuatro artículos que tratan sobre la transmisión de la ciencia entre Europa y América latina, hacia el final del siglo XIX, presentamos el articulo de J. Manuel González de la Pueña Puerta, Antonio Ramos Carrillo y Esteban Moreno Toral sobre la importación y la profesionalización de la farmacia en Cuba. La isla de Cuba fue una de las ultimas colonias de la Corona Española en América. Una de las consecuencias de esta prolongada presencia, es la actividad, hasta finales del siglo XIX, de instituciones tales que el Tribunal del Protomedicato, la Real Junta Superior Gubernativa y la Facultad de Farmacia, las cuales regulan el ejercicio de todas las ramas de la medicina. Esta regulación de la profesión que dura hasta 1889, es una de las características de la medicina cubana. Así, mientras que otros países de América latina tendrán que enfrentar la falta de instituciones reguladoras y de leyes para el ejercicio y reconocimiento oficial, la farmacia y la medicina 
cubanas comienzan el siglo con instituciones y legislaciones existentes para el ejercicio regular de las especialidades y sub-especialidades medicas.

Cambiando de siglo, los siguientes tres artículos tratan sobre la transmisión y la circulación del conocimiento en América latina durante la primera mitad del siglo XX. Comenzamos con el articulo de Yajaira Freites que nos ofrece un ejemplo de la circulación de conocimientos entre países latino americanos à través de la cooperación entre Argentina, Uruguay, México y Venezuela, frente a la emergencia sanitaria por controlar un enemigo común: la fiebre aftosa. La autora nos muestra como esta cooperación internacional sirvió, entre otras cosas, a la profesionalización de la veterinaria venezolana y a mejorar los dispositivos de acción nacionales e internacionales en materia de prevención y de control de epizootias. Un punto relevante de este trabajo es que nos muestra claramente que poseer el saber o las técnicas de diagnostico y profilaxis de las epizootias no es suficiente, es necesario adquirir y desarrollar la practica en las campañas sanitarias por medio de la colaboración y el intercambio internacional.

Por su parte, J. José Martín-Frenchilla analiza el desarrollo del dispositivo venezolano de salud publica y el rol que desempeñó la Fundación Rockefeller en la formación de ingenieros sanitarios y de profesionales de la salud publica entre 1926 y 1932. Así mismo, Martín-Frenchilla aborda el papel poco conocido de la participación de los médicos exiliados españoles en la construcción y desarrollo del sistema de salud publica venezolano à partir de 1938, es decir, después del retiro de la Fundación Rockefeller de Venezuela. El autor hace énfasis en las actividades de docencia llevadas a cabo por los médicos españoles y en las repercusiones que esta formación tuvo en la profesionalización de las actividades sanitarias en Venezuela.

Para finalizar, Elena Quiñones, Maria Peñaranda y Elena García, abordan la historia del psicoanálisis en Argentina y la influencia que el psicoanálisis francés y alemán tuvieron en ése país à través de Ángel Garma, exiliado español, alumno de Freud. Por otro lado las autoras establecen los hechos que permitieron la institucionalización y la profesionalización del psicoanálisis, no solamente en Argentina sino en todo el cono sur.

Nuestro objetivo al presentar este numero es de estimular la comunicación y los intercambios entre historiadores de la ciencia latinoamericanos o latinoamericanistas, extender los campos de estudio hacia una historia comparada de la introducción y circulación de las ciencias entre los pueblos americanos a fin de mostrar las particularidades de la transmisión científica de esta región, mas allá de la clasificación general y simplista de países periféricos.

Paris, mayo 2008. 